\title{
American pediatric society's 2017 John Howland award acceptance lecture: a tale of two toxicants: childhood exposure to lead and tobacco
}

\author{
Michael Weitzman ${ }^{1,2,3,4}$
}

\begin{abstract}
This article summarizes the presentation of the 2017 Howland Award to Michael Weitzman, MD, at the Annual Pediatric Academic Society Meetings. It summarizes the remarkable advances in understanding the effects and pathways of exposure of the two most common and pernicious of our nation's child environmental exposures, namely lead and tobacco. It also summarizes the profound effect of the translation of these findings into prudent and effective clinical and public health policies such that exposure to both has dramatically decreased over the past 40 years due to the tenacious activities of pediatricians, other child-related professionals, government agencies at all levels, and the American Academy of Pediatrics. Research and clinical activities, although essential, were not sufficient to produce these successes, but required extensive mentoring to produce a generation of academic pediatricians capable of conducting the requisite research, and extensive advocacy by pediatricians and others to overcome the formidable inertia and outright opposition to efforts to protect our children from these exposures. Moreover, the article highlights that both of these environmental exposures have roots in social and environmental injustice and neither is solved, and that there is no safe level of exposure to either of these toxicants.
\end{abstract}

I: is a great honor to be the recipient of this year's Howland

Award. I am fully cognizant that there are many others who are deserving of this honor. It brings me great pleasure to acknowledge the countless individuals who have significantly contributed to the work for which I am receiving this award, and in no small measure do I accept this award on their behalf. I also cannot overstate what a source of delight it is that my work has been deemed of sufficient importance to merit my inclusion with prior recipients who have made so many contributions to Pediatrics.

I am especially thankful that the world is full of children. I am truly appreciative to the American Pediatric Society, and in particular to Alex Trummel and her colleagues, for putting this event together. I am indebted to Bob Haggerty and Julius Richmond, two visionary former Howland Award winners and lifetime mentors of mine who pointed me in directions I never would have imagined, and who offered guidance, wisdom, and encouragement over the course of my career. I also am beholden to the myriad students and trainees whose boundless energy, enthusiasm, curiosity, and belief that we can change the world for the better have so inspired and instructed me. And of course, my greatest gratitude is to my two families-my family of origin that is now gone and which set me on the course that led to today, and most of all to my wife and children.

Each of us shares a number of causes: preventing and treating children's diseases while reducing childhood antecedents of adult disease and disability while promoting resilience, generosity, and empathy. To varying degrees these entail providing and overseeing services to children and families; uncovering new knowledge via research; training the next generation of pediatric practitioners, researchers, educators, and advocates; and working to translate new knowledge into effective and sustainable clinical and public practices and policies, which often entails working with others from outside the pediatric community. For those of us who are really, really lucky, and I surely am one of those, our work involves each of these elements.

I will very briefly describe advances that occurred over the course of the past century, and particularly during my career, in preventing and treating two of the most ubiquitous and pernicious of our children's physical environmental exposures, lead and tobacco. Both of these exposures are largely preventable, the result, initially, of ignoring their damaging effects and misperception that their damage occurred only among adults. Their recognition as child health problems required substantial conceptual leaps supported by extensive research. The persistence of both and the recrudescence of tobacco use and secondhand smoke (SHS) exposure are the result of beliefs and actions that all too often emanate from conscious or unconscious, spoken or unspoken disregard for the health of children and adults. In the case of lead, disdain,

\footnotetext{
${ }^{1}$ Department of Pediatrics, New York University School of Medicine, New York City, New York; ${ }^{2}$ Department of Environmental Medicine, New York University School of Medicine, New York City, New York; ${ }^{3}$ College of Global Public Health, New York University, New York City, New York; ${ }^{4}$ NYU/Abu Dhabi Public Health Research Center, Abu Dhabi, UAE. Correspondence: Michael Weitzman (Michael.weitzman@nyumc.org)

Received 2 August 2017; accepted 18 September 2017; advance online publication 25 October 2017. doi:10.1038/pr.2017.240
} 
antipathy, or indifference toward minorities and those living in poverty often is critical. Greed at every level is central to both of these two toxicants. So much of both child and adult health disparities, premature disability, and death are manmade, largely preventable, or can be greatly attenuated, if we have the knowledge-and we do have the knowledge-the desire, and the will.

\section{CHILDHOOD LEAD POISONING}

Progress in understanding and addressing childhood lead poisoning over the past 40 years has been truly remarkable. This progress has occurred in the following five specific areas:

- Pathways of exposure have been explicated, leading to the discovery of ways to largely abort childhood lead exposure $(1,2)$;

- The implementation of an extensive array of pediatric and governmental policies, regulations, and practices based on research $(2-5)$;

- These efforts have resulted in a truly profound decrease in children's exposure to lead and consequently blood lead levels (6);

- Discovery of adverse neurocognitive effects at lower and lower, and even, the lowest measurable levels of exposure $(1,3,4)$;

- A paradigm shift from treatment to prevention.

Although lead exposure can result from ingestion of numerous sources, as indicated by the recent water crisis in Flint Michigan (7) (Figure 1), the addition of lead to commercial paint in the 1880 s and to gasoline in the 1920 s greatly increased lead exposure of children in the developed world. Lead-contaminated household dust from chipping, peeling, and flaking lead-contaminated paint is the major source of children's exposure, as clearly demonstrated by research over the past 40 years $(1,4,8-10)$. However, when appropriately conducted, lead-based paint abatement can greatly reduce children's exposure $(3,11,12)$.

Figure 1 illustrates the astounding number of regulations fueled by knowledge of lead's untoward neurocognitive effects that have diminished lead exposure and the consequent profound decrease in children's blood lead levels, from a mean of $16 \mu \mathrm{g} / \mathrm{dl}$ in the early 1970 s to less than $1 \mu \mathrm{g} / \mathrm{dl}$ today (6).

Lead has been used for millennia and its adverse effects on adults have been known since the second century BC $(13,14)$, but much of the progress in terms of understanding and reducing childhood lead exposure has only occurred in the past 40-50 years. Figure 2 provides a time line of the remarkable array of discoveries on lead's deleterious effects on children's neurocognitive function. In 1904, Gibson first described lead poisoning among children, linked to peeling lead-based paint on verandas (15). The US pediatric community remained skeptical for the next 10 years, until Blackfan of Blackfan-Diamond Anemia renown accepted this (16). It would take almost a century before the enormity of this epidemic of subtle but serious neurocognitive impairments, chiefly among children of color living in poverty, was uncovered and accepted by the clinical and public health communities.

By the early Twenty-first century, it was widely accepted that blood lead levels $>10 \mu \mathrm{g} / \mathrm{dl}$ caused diminutions in IQ and a number of neurocognitive problems on a population basis. Over the past 20 years, a voluminous literature $(17,18)$ has consistently identified problems, such as increased rates of attention deficit hyperactivity disorder, impulsivity, disruptive and violent behavior, poor executive functioning, and shortterm memory, first at levels $<10 \mu \mathrm{g} / \mathrm{dl}$ ( (ref. 5)) then at $<5 \mu \mathrm{g} / \mathrm{dl}$, and now at the very lowest measurable levels of children's blood lead $(3,19)$. The Centers for Disease Control and Prevention consequently has repeatedly decreased its

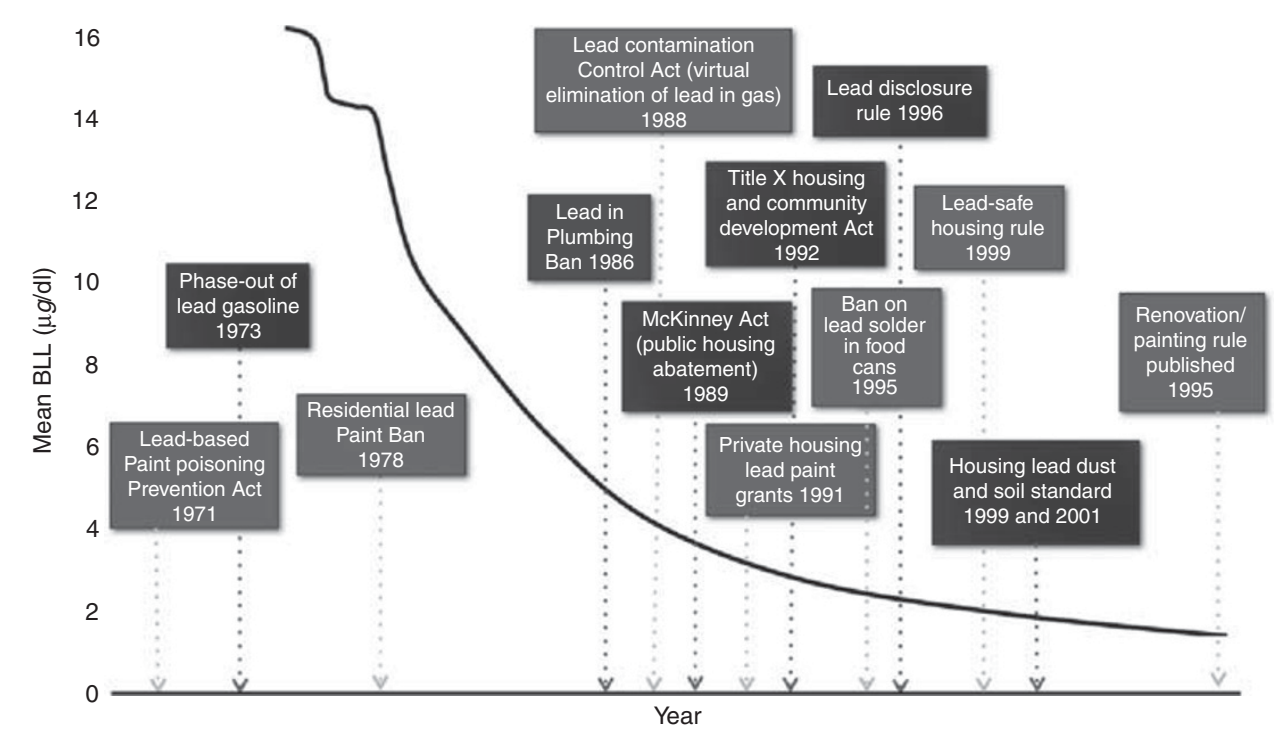

Figure 1. Decline in childhood blood lead levels and the legislations and regulations of multiple sources of exposure. Adapted from ref. (1). 


\section{A tale of two toxicants Review}

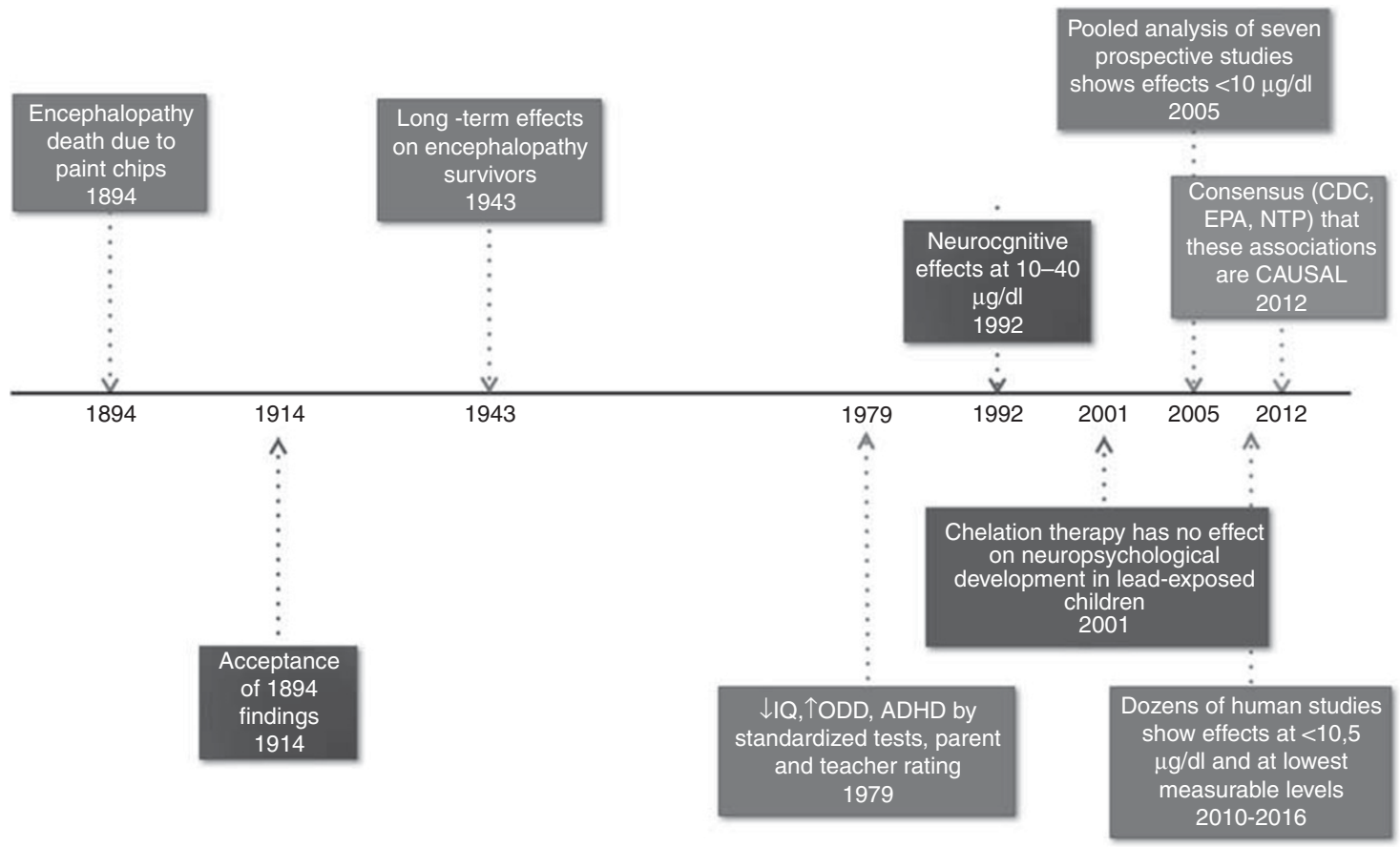

Figure 2. Landmark Discoveries of Lead's Neurocognitive Effects on Children.

level of concern from 60 to $>5 \mu \mathrm{g} / \mathrm{dl}$ currently, stating that there is no safe level of children's lead exposure (4). As chelation therapy also was shown to be ineffective in reversing the adverse effects of childhood lead exposure $(20,21)$, pediatric and public health strategies shifted from exclusively treating children with elevated lead levels to implementing far-reaching preventive efforts. Concerns about low-level lead exposure and demonstration of effective preventive approaches have been endorsed by authoritative bodies such as the US Environmental Protection Agency (3), the National Toxicological Program (19), and the American Academy of Pediatrics (1). However, the epidemic is not over, with 2 million children under the age of 5 still having elevated blood lead levels (22).

\section{CHILDREN AND TOBACCO EXPOSURE AND USE}

There also have been tremendous increases both in understanding and addressing tobacco and its effects on child and adolescent health over the past 40 years.

- Both rates of prenatal tobacco and childhood SHS exposure (23-27) and rates of use have been identified and, in part, explicated and influences on initiation have been tracked $(28,29)$

- Multiple adverse child effects have been uncovered at the lowest levels of exposure (29-33)

- Effective practices, policies, and regulations have been discovered and implemented to greatly reduce cigarette use (34-37), resulting in a profound decrease in exposure and initiation (38)

Tobacco use and exposure to SHS are the leading preventable causes of morbidity and mortality in the United
States and worldwide, killing more people than Tuberculosis, HIV, and Malaria combined $(39,40)$. More than 1 billion tobacco-related deaths have taken place in this century (41), and virtually all adults start smoking before 18 years of age (28), with the mean age of initiation in the United States being 13 years (28). Concern about untoward health consequences of cigarette smoking, exclusively of adults, began in the 1920s (ref. (42)) and were scientifically proven in the late 1940s and early 1950s (43-47); however, concern about ill effects on children did not begin in earnest for another 40 years (48-50). As is true of lead, there is no safe level of tobacco smoke exposure as stated by the Surgeon General of the US Public Health Service $(39,40)$.

Tobacco was used for centuries by Native Americans (51) and, by the Seventeenth century, tobacco use had spread across the world (42). In the 1880s, cigarettes began to be mass-manufactured, such that rates of cigarette use in the US went from $2 \%$ in 1900 to $46 \%$ (ref. (52)) by the time the first Surgeon General's Report on Smoking and Health was published in 1964, followed by a steady decline in tobacco use, until the uptake of new alternative tobacco products (ATPs, also called Alternative Nicotine Delivery Systems) approximately a decade ago.

The profound decline in cigarette use is a consequence of evidence-based clinical guidelines, regulations, and educational campaigns (Figure 2), but what led to the marked increase over the first 60 years of the Twentieth century in the first place? Part of it was changes in social norms. Edward Bernays, the nephew of Sigmund Freud and the inventor of advertising, orchestrated multiple efforts that contributed to this steady incline in tobacco use, including the 1929 Torches 
of Freedom March, in which women marched for gender equality with cigarettes as a symbol of women's emancipation (53). He also used doctors to promote cigarette sales (42) in the same way that they now are again being used to advertise new ATPs (54). As early as 50 years ago, he recognized the importance of targeting children and adolescents. Such advertising was banned by the landmark 1996 Master Settlement Agreement (with Howland Award Winner, Julius Richmond MD, my third year ward attending while I was in medical school, a key medical witness in the case). At the same time, David Kessler, then head of the US Food and Drug Administration (FDA) and also a pediatrician, described for the first time cigarettes as nicotine-delivery systems (55), thereby opening the door to FDA regulation of tobacco products (56).

Tobacco and children were on virtually no one's radar 30 years ago (29), except for the tobacco industry, which already was targeted to youth (e.g., Joe Camel) (57-59). Only a handful of articles about prenatal tobacco and childhood SHS exposure existed before 1990 (refs (60-62)), the same time an extensive literature began to emerge demonstrating that they are the leading preventable causes of low birthweight $(63,64)$, sudden infant death syndrome (65), recurrent otitis media $(66,67)$, asthma $(68,69)$, and reduced lung function $(70,71)$, as well as countless other problems, including but not limited to the metabolic syndrome (72,73), and food insecurity (74). Nicotine is the highly addictive psychoactive component of tobacco and it increases the proclivity to addiction to other drugs, such as heroin and cocaine (75).

Today, only $15 \%$ of adults (76) and $8 \%$ of adolescents (38) smoke cigarettes. The marked decrease in adolescent use of cigarettes has been more than offset by a meteoric rise in the use of electronic cigarettes (e-cigarettes) and hookahs (namely, waterpipes), which are often targeted to youth using many of the same techniques previously used for cigarettes (38). E-cigarettes were only introduced to the US market in 2007, but were quickly adopted and diversified into more than 100 different types of e-cigarettes and 7,000 different flavorings, with names that appeal to youth, such as strawberry cream pie, bubble gum, cotton candy, mojito, and sex on the beach. In the span of 6 years (2011-2016), past 30 day use of cigarettes among US individuals aged 18-24 decreased by $50 \%$ while hookah use increased by $17 \%$ and e-cigarette use increased by $553 \%$ (ref. (38)), such that there are more e-cigarette users than cigarette users in this age group (Table 1) and leading to widespread public health concern that e-cigarettes may renormalize smoking $(77,78)$.

Hookah-smoking results in far more dangerous levels of air pollutants than cigarette smoking (79-82) and both active hookah smoking and SHS are associated with major shortand long-term health effects (83-85). However, whether it leads to nicotine addiction, cigarette uptake, or cigarette cessation is still unknown $(86,87)$. Alarmingly, the public, as well as the medical community, perceives hookah as a safer and less addictive alternative to cigarettes (88-90). Evidence, however, suggests that hookah use may actually be as
Table 1. Estimated percentage of High school students who used tobacco products in the past 30 days 2011-2016(38) ${ }^{a}$

\begin{tabular}{lcccccc}
\hline & 2011 & 2012 & 2013 & 2014 & 2015 & 2016 \\
\hline Cigarettes & 15.8 & 14.0 & 12.7 & 9.2 & 9.3 & 8.0 \\
E-Cigarettes & 1.5 & 2.8 & 4.5 & 13.4 & 16.0 & 11.3 \\
Hookahs & 4.1 & 5.4 & 5.2 & 9.4 & 7.2 & 4.8 \\
\hline
\end{tabular}

${ }^{\mathrm{a}}$ Modified from ref. (38).

addictive $(91,92)$ and as harmful $(93,94)$ as cigarette use. A single hookah session can equate to smoking 100 or more cigarettes and yield greater levels of nicotine, tar, and carbon monoxide than cigarettes $(83,91,95-97)$. In contrast, there are only a handful of studies of active and passive exposure to aerosols generated by e-cigarette use (98-100), and there are no comparable studies concerning children or youth as of yet. Controversy continues to surround e-cigarettes, concerning their short- and long-term health effects, effectiveness for smoking cessation, and role in youth tobacco initiation. Many reputable organizations, including the Surgeon General (101), Centers for Disease Control and Prevention (102), World Health Organization $(103,104)$, FDA (105), American Academy of Pediatrics (106), and American Lung Association $(107,108)$ have all expressed concerns about e-cigarette and hookah use Figure 3.

\section{FINAL THOUGHTS}

Reductions in lead and tobacco exposure have had profound successes over the course of my career. These represent some of the greatest pediatric public health successes of their time. However, clinical care and solid and sustained research were not sufficient to help stem the tide of these two epidemics. This is a consequence of the tenacity of pediatricians working with committed colleagues in critical governmental agencies such as the Centers for Disease Control and Prevention, EPA, FDA HUD, and the Department of Justice, as well as the American Academy of Pediatrics, to overcome the inertia or outright opposition to efforts to protect our nation's children from these toxicants. It took advocacy at all levels of the community and government, valiant efforts by local health departments, and even testifying before Congress and serving as expert witnesses in federal law suits to make these two childhood epidemics be seen as tragic occurrences of our own making that could be greatly attenuated.

However, the work for these two childhood environmental problems is far from over and, despite their differences, both of these toxic exposures share numerous characteristics that may help illuminate future environmental exposure problems for children:

(1) They have been found to be the most common and dangerous of all of our children's toxic exposures, have caused great harm to generations across the past century, and there is no safe level of exposure to either of these toxicants;

(2) The discovery of exposure pathways and the dangers of these agents for children have been remarkably 


\section{A tale of two toxicants Review}

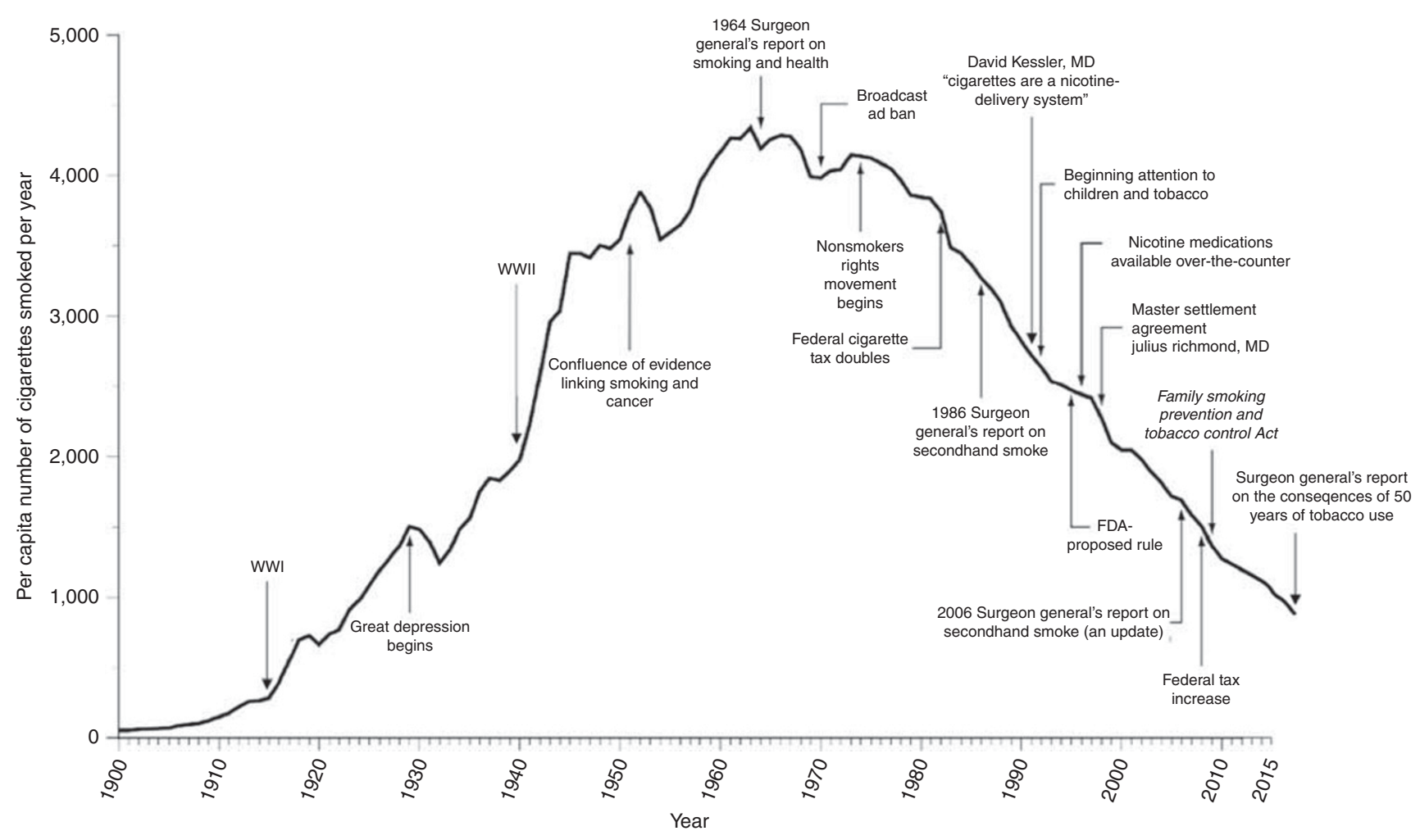

Figure 3. The $20^{\text {th }}$ Century Tobacco Epidemic. Adapted from ref. (29).

extensive, but have lagged far behind those for adults and, although both are major antecedents of adult health, they have rarely been conceptualized as such;

(3) Yet, children and adolescents have been allowed to be exposed for decades after these exposures were found to be harmful, due in large part to corporate greed abetted by the invention and pervasive use of advertising that has been central to these two epidemics;

(4) Extraordinary progress over the past 4 decades has resulted in astounding reductions in exposure to both, but substantial numbers of exposed and damaged youth still exist and both still pose major childhood exposures that urgently must be met;

(5) Pediatricians have been, and will continue to be, central collaborators in addressing such preventable epidemics.

There continue to be questions as to how we will we deal with the vast number of homes that still have lead-based paint and lead-based paint hazards or the epidemic increase in the use of new ATPs that threaten to eradicate almost 60 years of successful antitobacco efforts. If we earnestly want a nationwide infrastructure project that would protect millions of our children, add to their future academic and vocational success, create thousands of jobs, and improve the quality of homes, why not abate homes and address lead in water? Decades ago, the visionary researcher and advocate, Herbert Needleman, one of the most important individuals in our successes concerning childhood lead exposure pointed this out. Our failure to adopt this proposal speaks directly to two critical points: our shameful and all too frequent failure to act to protect our children and the public at large from dangerous environmental exposures, and just how difficult it is to change existing policies and implement them in an effective manner. Similarly, we urgently need research on reasons for ATP initiation, the health effects on users and those passively exposed, and then implementation of evidence-based practices and policies to stem the tide of their use, much as has been done for cigarettes using taxation, restriction of advertising, inclusion in clean air acts, and educational campaigns.

And so I end with this quote from Rudolph Virchow, the "Father" of Modern Pathology and Social Medicine:

"If medicine is to fulfill her great task, then she must enter the political and social spheres... Physicians are the natural attorneys of the poor and the social problems should largely be solved by them." Pediatricians, I am proud to say, driven by a sense of social and environmental justice as well as profound concern about child well-being, have acted on these as clinicians, researchers, educators, and public health officials, with great effect. What a noble profession we are part of, and how fortunate we all are to have work filled with purpose, never-ending learning, teaching, discovery, and wonderful colleagues, all in the cause of helping our children and their families. 
Again, I am ever so grateful for this wonderful career in Pediatrics, and for now being so honored as the recipient of the 2017 Howland Award.

Disclosure: The author declares no conflict of interest.

\section{REFERENCES}

1. AAP Council on Environmental Health. Prevention of childhood lead toxicity. Pediatrics 2016;38:e20161493.

2. Office of Healthy Homes and Lead Hazard Control Guidelines for the Evaluation and Control of Lead-Based Paint Hazards in Housing Washington DC. 2nd edn, US Department of Housing and Urban Development, 2012.

3. National Center for Environmental Assessment Integrated Science Assessment for Lead. Triangle Park, NC: Office of Research and Development, Research, US Environmental Protection Agency, 2013.

4. Advisory Committee on Childhood Lead Poisoning Prevention Low Level Lead Exposure Harms Children: A Renewed Call for Primary Prevention. Atlanta, GA: Centers for Disease Control and Prevention, 2012.

5. Committee on Measuring Lead in Critical Populations Measuring Lead Exposure in Infants, Children, and Other Sensitive Populations. Washington, DC: National Academy Press, 1993.

6. Raymond J, Brown MJ. Childhood blood lead levels in children aged $<5$ years - United States, 2009-2014. MMWR Surveill Summ 2017;66:1-10.

7. Hanna-Attisha M, LaChance J, Sadler R, Schnepp A. Elevated blood lead levels in children associated with the Flint drinking water crisis: a spatial analysis of risk and public health response. Am J Public Health 2016;106:283-90.

8. Jacobs D, Clickner R, Zhou J, et al. The prevalence of lead based paint hazards in US housing. Environ Health Perspect 2002;110:A599-606.

9. Dixon S, Gaitens J, Jacobs D, et al. Exposure of US children to residential dust lead 1999-2004: II. The contribution of lead-contaminated dust to children's blood lead levels.. Environ Health Perspect 2009;117:468-74.

10. Lanphear BP, Matte $T$, Rogers J, et al. The contribution of leadcontaminated house dust and residential soil to children's blood lead levels. Environ Res 1998;79:516-68.

11. Weitzman M, Aschengrau A, Bellinger D, Jones R, Hamlin JS, Beiser A. Lead-contaminated soil abatement and urban children's blood lead levels. J Am Med Assoc 1993;269:1647-54.

12. Farfel MR, Chisolm JJ Jr., Rohde CA. The longer-term effectiveness of residential lead paint abatement. Environ Res 1994;66:217-.

13. Eisinger J. Lead and wine. Eberhard Gockel and the colica Pictonum.. Med Hist 1982;26:279-302.

14. Riva MA, Sironi VA, Fano D, Cesana G. Workers' health conditions in the Greco-Roman world: the contribution of non-medical sources. Arch Environ Occup Health 2011;66:54-.

15. Gibson JL. A plea for painted railings and painted walls of rooms as the source of lead poisoning amongst Queensland children.. Public Health Rep 2005;120:301-4.

16. Thomas HM, Blackfan KD. Recurrent meningitis, due to lead, in a child of five years. Am J Dis Children 1914;VIII:377-80.

17. Lanphear BP, Hornung R, Khoury J, et al. Low-level environmental lead exposure and children's intellectual function: an international pooled analysis. Environ Health Perspect 2005;113:894-9.

18. Needleman HL, Gunnoe C, Leviton A, et al. Deficits in psychologic and classroom performance of children with elevated dentine lead levels. N Engl J Med 1979;300:689-95.

19. National Toxicology Program NTP Monograph: Health Effects Of LowLevel Lead. Report 2330-1279 (Print) 2330-1279. Washington, DC: US Department of Health and Human Services, 2012.

20. Dietrich K, Ware J, Saiganik M, et al. Treatment of lead-exposed children clinical trial group effect of chelation therapy on the neuropsychological and behavioral development of lead-exposed children after school entry. Pediatrics 2004;114:19-26.
21. Rogan WJ, Dietrich KN, Ware JH, et al. The effect of chelation therapy with succimer on neuropsychological development in children exposed to lead. N Engl J Med 2001;344:1421-6.

22. Department of Health and Human Services CDC's national surveillance data (1997-2015): Tested and confirmed elevated blood lead levels by state, year and blood lead level group for children $<72$ months. Centers for Disease Control and Prevention, National Center for Environmental Health, 2016.

23. Hamilton BE, Martin JA, Ventura SJ. Births: preliminary data for 2012. Natl Vital Stat Rep 2013;62:1-20.

24. World Health Organization Report of the Global Tobacco Epidemic: Implementing Smoke-Free Environments. Geneva: World Health Organization, 2009.

25. Homa DM, Neff LJ, King BA, et al. Vital signs: disparities in nonsmokers' exposure to secondhand smoke-United States, 19992012. MMWR Morb Mortal Wkly Rep 2015;64:103-8.

26. Quinto KB, Kit BK, Lukacs SL, Akinbami LJ. Environmental tobacco smoke exposure in children aged 3-19 years with and without asthma in the United States, 1999-2010. NCHS Data Brief No. 126. Atlanta, GA: US Department of Health and Human Services, Centers for Disease Control and Prevention, 2013.

27. Pirkle JL, Flegal KM, Bernert JT, Brody DJ, Etzel RA, Maurer KR. Exposure of the US population to environmental tobacco smoke: the Third National Health and Nutrition Examination Survey, 1988 to 1991. JAMA 1996;275:1233-40.

28. National Center for Chronic Disease, Prevention Health Promotion Office on Smoking Health Preventing Tobacco Use Among Youth and Young Adults: A Report of the Surgeon General. Atlanta, GA: Centers for Disease Control and Prevention, 2012.

29. National Center for Chronic Disease, Prevention Health Promotion Office on Smoking Health The Health Consequences of Smoking-50 Years of Progress: A Report of the Surgeon General. Atlanta, GA: Centers for Disease Control and Prevention, 2014.

30. Chen Y, Li WX, Yu SZ, Qian WH. Chang-Ning epidemiological study of children's health: I: passive smoking and children's respiratory diseases. Int J Epidemiol 1988;17:348-55.

31. Zhou S, Rosenthal DG, Sherman S, Zelikoff J, Gordon T, Weitzman M. Physical, behavioral, and cognitive effects of prenatal tobacco and postnatal secondhand smoke exposure. Curr Probl Pediatr Adolesc Health Care 2014;44:219-41.

32. Feldman J, Shenker IR, Etzel RA, et al. Passive smoking alters lipid profiles in adolescents. Pediatrics 1991;88:259-64.

33. Strulovici-Barel Y, Omberg L, O'Mahony M, et al. Threshold of biologic responses of the small airway epithelium to low levels of tobacco smoke. Am J Respir Crit Care Med 2010;182:1524-32.

34. Been JV, Nurmatov UB, Cox B, Nawrot TS, van Schayck CP, Sheikh A. Effect of smoke-free legislation on perinatal and child health: a systematic review and meta-analysis. Lancet 2014;383:1549-60.

35. Mills AL, Messer K, Gilpin EA, Pierce JP. The effect of smoke-free homes on adult smoking behavior: a review. Nicotine Tob Res 2009;11: 1131-41.

36. van Hasselt $M$, Kruger $J$, Han B, et al. The relation between tobacco taxes and youth and young adult smoking: what happened following the 2009 U.S. federal tax increase on cigarettes? Addict Behav 2015;45:104-9.

37. Frazer K, McHugh J, Callinan JE, Kelleher C. Impact of institutional smoking bans on reducing harms and secondhand smoke exposure. Cochrane Database Syst Rev 2016: Cd011856.

38. Jamal A, Gentzke A, Hu SS, et al. Tobacco Use among middle and high school students - United States, 2011-2016. MMWR Morb Mortal Wkly Rep 2017;66:597-603.

39. National Center for Chronic Disease, Prevention Health Promotion Office on Smoking Health The Health Consequences of Involuntary Exposure to Tobacco Smoke: A Report of the Surgeon General. Atlanta, GA: Centers for Disease Control and Prevention, 2006.

40. Samet JM. Tobacco smoking: the leading cause of preventable disease worldwide. Thorac Surg Clin 2013;23:103-2. 
41. Peto R, Lopez DA. Future worldwide health effects of current smoking patternsIn:Koop C, Pearson C, Schwarz Meds. Tobacco and Public Health: Science and Policy. Jossey-Bass: San Francisco: Wiley); 2001: $154-61$.

42. Brandt A. The Cigarette Century: the rise, fall, and deadly persistence of the product that defined America. Basic Books: New York, 2007.

43. Doll R, Hill AB. Smoking and carcinoma of the lung; preliminary report. Br Med J 1950;2:739-48.

44. Levin ML, Goldstein H, Gerhardt PR. Cancer and tobacco smoking; a preliminary report. J Am Med Assoc 1950;143:336-8.

45. Schrek R, Baker LA, et al. Tobacco smoking as an etiologic factor in disease; cancer. Cancer Res 1950;10:49-58.

46. Doll R, Hill AB. The mortality of doctors in relation to their smoking habits. Br Med J 1954;1:1451.

47. Hammond EC, Horn D. The relationship between human smoking habits and death rates: a follow-up study of 187,766 men. J Am Med Assoc 1954;155:1316-28.

48. Breslau N, Kilbey MM, Andreski P. DSM-III-R nicotine dependence in young adults: prevalence, correlates and associated psychiatric disorders. Addiction 1994;89:743-54.

49. McNeill AD, West RJ, Jarvis M, Jackson P, Bryant A. Cigarette withdrawal symptoms in adolescent smokers. Psychopharmacology 1986;90:533-6.

50. Rojas NL, Killen JD, Haydel KF, Robinson TN. Nicotine dependence among adolescent smokers. Arch Pediatr Adolesc Med 1998;152: $151-6$.

51. Kulikoff A. Tobacco and Slaves: the Development of Southern Cultures in the Chesapeake, 1680-1800. Chapel Hill: University of North Carolina Press, 1986.

52. National Cancer Institute Smoking and Tobacco Control Monograph No. 8: Changes in Cigarette-related disease Risks and Their Implications for Prevention and Control. US: US Department of Health and Human Services, Public Health Service, National Institutes of Health, National Cancer Institute, 2003.

53. Edward Bernays to George Washington Hill Edward Bernays Manuscript Collection: Bernays Collection. In: Congress Lo, ed, Box 56, 1929.

54. Electronic Advertising Themes Stanford Research Into the Impact of Marketing, 2017 (http://tobacco.stanford.edu/tobacco_main/main_ecigs. php.). Accessed 27 July 2017..

55. Kessler DA, Natanblut SL, Wilkenfeld JP, et al. Nicotine addiction: a pediatric disease. J Pediatr 1997;130:518-24.

56. Kessler DA, Barnett PS, Witt A, Zeller MR, Mande JR, Schultz WB. The legal and scientific basis for FDA's assertion of jurisdiction over cigarettes and smokeless tobacco. J Am Med Assoc 1997;277:405-9.

57. DiFranza JR, Richards JW, Paulman PM, et al. RJR Nabisco's cartoon camel promotes camel cigarettes to children. J Am Med Assoc 1991;266: 3149-53.

58. Lears J. Fables of Abundance: a Cultural History of Advertising in America. Basic Books, 1994.

59. Porter PG. Advertising in the early cigarette industry: W. Duke, Sons \& Company of Durham. North Carolina Hist Rev 1971;69:31-23.

60. Etzel RA, Greenberg RA, Haley NJ, Loda FA. Urine cotinine excretion in neonates exposed to tobacco smoke products in utero. J Pediatr 1985;107:146-8.

61. Greenberg RA, Haley NJ, Etzel RA, Loda FA. Measuring the exposure of infants to tobacco smoke. Nicotine and cotinine in urine and saliva. $\mathrm{N}$ Engl J Med 1984;310:1075-8.

62. Pattishall EN, Strope GL, Etzel RA, Helms RW, Haley NJ, Denny FW. Serum cotinine as a measure of tobacco smoke exposure in children. Am J Dis Children 1985;139:1101-4.

63. Dejmek J, Solansk y I, Podrazilová K, Srám RJ. The exposure of nonsmoking and smoking mothers to environmental tobacco smoke during different gestational phases and fetal growth. Environ Health Perspect 2002;110:601-6.

64. Kramer MS. Determinants of low birth weight: methodological assessment and meta-analysis. Bull World Health Org 1987;65: 663-737.
65. Fleming P, Blair PS. Sudden infant death syndrome and parental smoking. Early Hum Dev 2007;83:721-5.

66. Ilicali OC, Keles N, De er K, Sa un OF, Guldiken Y. Evaluation of the effect of passive smoking on otitis media in children by an objective method: urinary cotinine analysis. Laryngoscope 2001;111:163-7.

67. Etzel RA, Pattishall EN, Haley NJ, Fletcher RH, Henderson FW. Passive smoking and middle ear effusion among children in day care. Pediatrics 1992;90:228-32.

68. Cook DG, Strachan DP. Health effects of passive smoking. 3. Parental smoking and prevalence of respiratory symptoms and asthma in school age children. Thorax 1997;52:1081-94.

69. DiFranza JR, Lew RA. Morbidity and mortality in children associated with the use of tobacco products by other people. Pediatrics 1996;97: $560-8$.

70. Colley JR. Respiratory symptoms in children and parental smoking and phlegm production. Br Med J 1974;2:201-4.

71. Leeder SR, Corkhill R, Irwig LM, Holland WW, Colley JR. Influence of family factors on the incidence of lower respiratory illness during the first year of life. Br J Prev Soc Med 1976;30:203-12.

72. McConnell R, Shen E, Gilliland FD, et al. A longitudinal cohort study of body mass index and childhood exposure to secondhand tobacco smoke and air pollution: the Southern California Children's Health Study. Environ Health Perspect 2015;123:360-6.

73. Weitzman M, Cook S, Auinger P, et al. Tobacco smoke exposure is associated with the metabolic syndrome in adolescents. Circulation 2005;112:862-9.

74. Cutler-Triggs C, Fryer GE, Miyoshi TJ, Weitzman M. Increased rates and severity of child and adult food insecurity in households with adult smokers. Arch Pediatr Adolesc Med 2008;162:1056-62.

75. Kandel DB, Kandel ER. A molecular basis for nicotine as a gateway drug. N Engl J Med 2014;371:2038-9.

76. Jamal A, King BA, Neff LJ, Babb SD, Graffunder C. Current cigarette smoking among adults - United States, 2005-2015. MMWR Morb Mortal Wkly Rep 2016;65:1205-1.

77. Fairchild AL, Bayer R, Colgrove J. The renormalization of smoking? E-cigarettes and the tobacco "endgame". N Engl J Med 2014;370:293-5.

78. Voigt K. Smoking norms and the regulation of e-cigarettes. Am J Public Health 2015;105:1967-72.

79. Cobb CO, Vansickel AR, Blank MD, Jentink K, Travers MJ, Eissenberg T. Indoor air quality in Virginia waterpipe cafes. Tob Control 2013;22: $338-43$.

80. Fiala SC, Morris DS, Pawlak RL. Measuring indoor air quality of hookah lounges. Am J Public Health 2012;102:2043-5.

81. Zhou S, Cawkwell P, Gordon T, et al. Air quality in New York city hookah bars. Tob Control 2015;24:198.

82. Weitzman M, Yusufali AH, Bali F, et al. Effects of hookah smoking on indoor air quality in homes. Tob Control 2017;26:586.

83. Akl EA, Gaddam S, Gunukula SK, Honeine R, Jaoude PA, Irani J. The effects of waterpipe tobacco smoking on health outcomes: a systematic review. Int J Epidemiol 2010;39:834-57.

84. El-Zaatari ZM, Chami HA, Zaatari GS. Health effects associated with waterpipe smoking. Tob Control 2015;24 (Suppl 1): i31-43.

85. Kumar SR, Davies S, Weitzman M, Sherman S. A review of air quality, biological indicators and health effects of second-hand waterpipe smoke exposure. Tob Control 2014;24 (Suppl 1): i54-9.

86. Hartmann-Boyce J, McRobbie H, Bullen C, Begh R, Stead LF, Hajek P. Electronic cigarettes for smoking cessation. Cochrane Database Syst Rev 2016;9:CD010216.

87. Walton KM, Abrams DB, Bailey WC, et al. NIH electronic cigarette workshop: developing a research agenda. Nicotine Tob Res 2015;17: 259-69.

88. Primack BA, Sidani J, Agarwal AA, Shadel WG, Donny EC, Eissenberg TE. Prevalence of and associations with waterpipe tobacco smoking among U.S. university students. Ann Behav Med 2008;36:81-6.

89. Roskin J, Aveyard P. Canadian and English students' beliefs about waterpipe smoking: a qualitative study. BMC Public Health 2009;9:10. 
90. Zhou S, Van Devanter N, Fenstermaker M, Cawkwell P, Sherman S, Weitzman M. A study of the use, knowledge, and beliefs about cigarettes and alternative tobacco products among students at one U.S. medical school. Acad Med 2015.

91. Cobb CO, Shihadeh A, Weaver MF, Eissenberg T. Waterpipe tobacco smoking and cigarette smoking: a direct comparison of toxicant exposure and subjective effects. Nicotine Tob Res 2011;13:78-87.

92. Noonan D, Kulbok PA. New tobacco trends: waterpipe (hookah) smoking and implications for healthcare providers. J Am Acad Nurs Pract 2009;21:258-60.

93. Eissenberg T, Shihadeh A. Waterpipe tobacco and cigarette smoking: direct comparison of toxicant exposure. Am J Prev Med 2009;37:518-23.

94. Knishkowy B, Amitai Y. Water-pipe (narghile) smoking: an emerging health risk behavior. Pediatrics 2005;116:e113-9.

95. Blank MD, Cobb CO, Kilgalen B, et al. Acute effects of waterpipe tobacco smoking: a double-blind, placebo-control study. Drug Alcohol Depend 2011;116:102-9.

96. Hawari FI, Obeidat NA, Ayub H, et al. The acute effects of waterpipe smoking on lung function and exercise capacity in a pilot study of healthy participants. Inhalation Toxicol 2013;25:492-7.

97. Maziak W, Rastam S, Ibrahim I, Ward KD, Shihadeh A, Eissenberg T. $\mathrm{CO}$ exposure, puff topography, and subjective effects in waterpipe tobacco smokers. Nicotine Tob Res 2009;11:806-11.

98. Ballbe M, Martinez-Sanchez JM, Sureda X, et al. Cigarettes vs. e-cigarettes: passive exposure at home measured by means of airborne marker and biomarkers. Environ Res 2014;135:76-80.
99. Fuoco FC, Buonanno G, Stabile L, Vigo P. Influential parameters on particle concentration and size distribution in the mainstream of e-cigarettes. Environ Pollut 2014;184:523-9.

100. Ingebrethsen BJ, Cole SK, Alderman SL. Electronic cigarette aerosol particle size distribution measurements. Inhalation Toxicol 2012;24: 976-84.

101. US Department of Health and Human Services. E-Cigarette use among youth and young adults - Executive summary: A report of the surgeon general. Rockville, MD: US Department of Health and Human Services, Centers for Disease Control and Prevention, National Center for Chronic Disease Prevention and Health Promotion, Office on Smoking and Health, 2016..

102. CDC Office on Smoking and Health. E-cigarette information: Centers for Disease Control, 2015.

103. World Health Organization Electronic nicotine deliery systems WHO Framework Convention on Tobacco Control, 2014.

104. WHOStudy Group on Tobacco Product RegulationWaterpipe Tobacco Smoking: Health Effects, Research Needs and Recommended Actions by Regulators. World Health Organization, 2005.

105. Federal Drug Administration Recognize Tobacco in its Many Forms FDA Consumer Health Information, 2014.

106. Walley SC, Jenssen BP. Electronic nicotine delivery systems. Pediatrics 2015;136:1018-26.

107. American Lung Association Statement on e-cigarettes: American Lung Association, 2015.

108. American Lung Association Tobacco Policy Trend Alert: An Emerging Deadly Trend: Waterpipe Tobacco Use, 2007. 